\title{
La importancia del concepto de frontera para los estudios de género: un análisis
}

\section{sobre las travestis}

\author{
A importância do conceito de fronteira para os estudos de gênero: uma abordagem sobre as \\ travestis
}

The importance of the concept of border for gender studies: an approach on transvestite

Recibido: 27/08/2020 | Revisado: 06/09/2020 | Acepto: 09/03/2021 | Publicado: 16/03/2021

\author{
Melissa Salinas Ruiz \\ ORCID: https://orcid.org/0000-0002-7093-3215 \\ Universidade Estadual do Oeste do Paraná, Brasil \\ E-mail: m_salinas@hotmail.com \\ Fábio Lopes Alves \\ ORCID: http://orcid.org/0000-0002-2114-3831 \\ Universidade Estadual do Oeste do Paraná, Brasil \\ E-mail: fabiobidu@hotmail.com
}

\begin{abstract}
Resumen
El interés académico en problematizar la normatividad de género sufrió un relevante aumento al final del siglo XX, influenciado por los trabajos de teóricos de género y queer. Consecuentemente, se incrementan las investigaciones sobre identidades cis divergentes, como de las travestis brasileñas. Las travestis subvierten el género binario al incorporar aspectos de feminidad a otros socialmente considerados masculinos, a ejemplo del pene. Al evidenciar la posibilidad de transitar entre dos polos que el sistema de género considera mutuamente excluyentes, surge el interés por conocer de qué maneras los cruces fronterizos están presentes en las vivencias travestis. Por tanto, este artículo utiliza una investigación bibliográfica y tiene como objetivo general discutir la importancia de los tránsitos fronterizos en la construcción de la identidad travesti, utilizando un concepto simbólico y geopolítico de frontera. De esta manera, los objetivos específicos de esta propuesta son discutir sobre travestis, abordar la influencia de los centros urbanos en el proceso de transformación de las travestis, comprender el prestigio de la categoría emica europea. Se concluye que distintos tipos de desplazamiento fronterizo integran etapas relevantes de la existencia de los travestis, pues es a través de estos tránsitos que adquieren un capital cultural y financiero que les brinda, además de prestigio, mejores condiciones de vida.
\end{abstract}

Palabras clave: Género; Frontera; Travesti.

\section{Resumo}

$\mathrm{O}$ interesse acadêmico em problematizar a normatividade de gênero aumentou consideravelmente ao final do século $\mathrm{XX}$, influenciado por teóricos de gênero e queer. Consequentemente, incrementam-se os estudos sobre identidades cis divergentes, como das travestis brasileiras. As travestis subvertem o gênero binário ao incorporar aspectos de feminilidade a outros socialmente considerados masculinos, como possuir um pênis. Ao evidenciar a possibilidade de transitar entre dois polos que o sistema de gênero considera mutualmente excludentes, surge o interesse em conhecer de quais as maneiras os cruzamentos fronteiriços estão presentes nas vivências travestis. Portanto, este artigo usa a pesquisa bibliográfica e possui o objetivo geral de discutir a importância dos trânsitos fronteiriços na construção identitária travesti, recorrendo a um conceito simbólico e geopolítico de fronteira. Dessa maneira, os objetivos específicos desta proposta são discorrer sobre travestilidade, tratar da influência dos centros urbanos no processo de transformação das travestis, compreender o prestígio da categoria êmica europeia. Conclui que diversos tipos de deslocamentos fronteiriços integram etapas relevantes da existência travesti, pois é por meio desses trânsitos que elas adquirem capital cultural e financeiro que lhes proporciona, além de prestígio, melhores condições de vida.

Palavras-chave: Gênero; Fronteira; Travesti.

\begin{abstract}
Academic interest in problematizing gender normativity increased considerably at the end of the 20th century, influenced by gender and queer theorists. Consequently, studies on cis divergent identities are increasing, such as that of Brazilian transvestites. Transvestites subvert the binary gender by incorporating aspects of femininity to others socially considered masculine, such as having a penis. By highlighting the possibility of moving between two poles that the gender system considers mutually exclusive, interest arises in knowing the ways in which border crossings are present in transvestite experiences. Therefore, this article uses bibliographic research and has the general objective of
\end{abstract}


discussing the importance of border transits in the transvestite identity construction, using a symbolic and geopolitical concept of border. In this way, the specific objectives of this proposal are to discuss transvestites, address the influence of urban centers on the transformation process of transvestites, understand the prestige of the European emic category. It concludes that different types of border displacement integrate relevant stages of the transvestite existence, because it is through these transits that they acquire cultural and financial capital that provides them, in addition to prestige, better living conditions.

Keywords: Gender; Border; Transvestite.

\section{Introducción}

Al hablar de las identidades que viven y performan el género de modos distintos a la norma cisgénero, suele recordarse a las brasileñas travestis. Estudiadas por teóricos como Benedetti (2005), Duque (2009) y Leite Junior (2014), las travestis brasileñas despiertan interés académico tanto por el modo peculiar en que perciben su identidad de género - pues no se consideran hombres ni mujeres - como por la intensa labor que realizan al modificar sus cuerpos (Pelúcio, 2005a).

Los tránsitos fronterizos marcan las vidas travestis en distintos momentos. En principio, se observa la manera en que cruzan las fronteras de género, apropiándose de la feminidad e incorporándola de maneras peculiares (Kulick, 2008). El cruce de divisas geográficas también es fundamental en la construcción de la travestilidad, pues salen de pequeñas ciudades hacia grandes centros urbanos, en los cuales dejarán de ser gayzinhos y se convertirán en travestis (Pelúcio, 2005a). Por fin, si es que alcanzan éxito, ellas partirán rumbo a Europa, donde se tornarán "europeas", categoría êmica utilizada para nombrar a las travestis que van a Europa y pasan a incorporar todo el lujo y sofisticación del viejo continente.

Considerando lo expuesto, este trabajo discute cómo la construcción de la travestilidad brasileña es influenciada por esos tránsitos fronterizos, para tanto adoptando un concepto de frontera poliforme (Almeida, 2005), con sentido geográfico, político y también social. En consecuencia, este análisis discute los límites establecidos por la estructura de género hegemónica y la manera en que las vivencias cis divergentes los atraviesan. A la misma vez, recurre al concepto geopolítico de frontera cuando discute migraciones dentro de Brasil y el tránsito de las travestis hacia Europa.

Por tanto, esta propuesta empieza hablando al respecto del sistema de género binario y sus implicaciones para las corporalidades que lo desafían, con base en Butler (2004; 2013; 2014) y Miskolci (2009). Luego, expone algunos aspectos que permiten afirmar que las travestis cruzan las fronteras de género, amparándose en Kulick (2008) y Pelúcio (2005a; 2005b; 2011) para justificar la argumentación. Finalmente, recurre a la noción de migraciones travestis planteada por Cabral (2012) y Vale (2005) con él objetivo de explicar cómo los dislocamientos fronterizos, dentro y fuera de Brasil, son etapas importantes para la formación de las travestis brasileñas.

\section{Metodología}

Teniendo en cuenta que parte de un problema de pesquisa que se propone a saber cuál es la importancia del concepto de fronteras para las travestis brasileñas, el presente estudio utiliza la metodología de pesquisa bibliográfica cualitativa, por lo cual selecciona su referencial teórico siguiendo criterios temáticos y de relevancia de la contribución dentro de los estudios queer y de género. Así, prioriza contribuciones que siguen los ejes temáticos referentes a las intersecciones entre travestilidad, migraciones y fronteras de género, las cuales fueron encontradas por medio de pesquisas en herramientas de busca específicas para trabajos académicos, como el Google Scholar y el Banco de Teses e Dissertações da Capes.

Además, la lectura de los materiales fue orientada de acuerdo a los objetivos específicos delimitados: a) constatar si es posible pensar en las normas de género cómo "fronteras" y cómo las travestis las atravesarían; b) cual es el papel de los grandes centros urbanos para la construcción de esa travestilidad; c) cómo la categoría êmica europea incorpora los aspectos de género y territoriales en la creación de una identidad considerada de prestigio. 
Gracias al vínculo entre travestilidad y disidencia de género, la perspectiva de género y queer, conforme defendida por Butler (2004), orienta el análisis del referencial bibliográfico. De esa manera, al discutir sobre las relaciones de género se parte de la conciencia de que estas son fluidas e influenciadas por la lectura social que se hace de los cuerpos, géneros y sexualidades, o sea, comprendiendo el carácter construido de elementos que se suelen considerar "naturales".

Por dar énfasis a la experiencia de travestis brasileñas, este trabajo se ampara, principalmente, en teóricos brasileños que analizan cómo las manifestaciones de ese género se relacionan a aspectos locales. Entre ellos, se destacan los trabajos de Larissa Pelúcio (2005a; 2005b; 2007; 2010; 2011), Tiago Duque (2009; 2018) y Berenice Bento (2017), pues son autores cuyas trayectorias académicas se dedican específicamente a analizar las manifestaciones brasileñas del género travesti, razón por la cual se considera que sus propuestas teóricas poseen gran impacto dentro de los estudios brasileños de género. Otro indicador de la relevancia de los teóricos seleccionados fue comprobada al observar su recurrencia en periódicos especializados en el debate de género - como los Cadernos Pagu, de la Universidade Estadual de Campinas - y la frecuencia con que son mencionados en tesis y disertaciones del área. Por ello, aludidos teóricos respaldan las consideraciones referentes a la manera en que se construye la identidad travesti, por lo cual se utilizan innúmeros de sus conceptos, a ejemplo de "noche", gayzinho, mãe, madrinha y "europea".

La importancia que los estudios de género atribuyen a la travestilidad produce un relevante número de trabajos científicos extranjeros sobre el tema. Entre los más destacados, consta la etnografía del sueco Don Kulick (2008), realizada en la ciudad brasileña de Salvador, a partir de la cual se conoce el vínculo entre experiencias travestis y relacionamientos afectivos y sexuales. Llevando en consideración que la mayoría de estudios sobre el tema son de las últimas décadas del siglo XX e inicio del siglo XXI, el trabajo del autor propicia una interesante noción a respecto de cómo es importante el recorte temporal en los análisis, una vez que las expresiones de género son fluidas.

Gracias a que se emplea el término "frontera" en su aspecto poliforme, se opta por la clásica explicación de Butler (2004) referente a género y performance para dar a entender cómo el género opera en la sociedad de acuerdo a normas performativas que, en este trabajo, son equiparadas a límites. Otros conceptos clave para esta propuesta son "vuelo de la belleza” (Vale, 2005) y "migraciones travestis" (Cabral, 2012), los cuales posibilitan pensar en las experiencias de género en intersección con los tránsitos geopolíticos.

Conforme mencionado, la producción teórica sobre el género travesti se caracteriza por su carácter reciente, razón por la cual no se utilizó un límite temporal como criterio para seleccionar el referencial teórico. Entre tanto, por la creciente importancia que el tema viene adquiriendo en la comunidad científica, la mayoría de los trabajos a los cuales se recurre son estudios realizados entre el período de 2000 y 2017. Por la misma razón, no se buscó delimitar el tipo de fuente al que se recurriría, priorizando el parámetro temático, lo cual ocasionó que la presente propuesta se embace, principalmente, en tesis, artículos científicos y libros.

Acerca de la relevancia de los trabajos que utilizan el abordaje bibliográfico, Lima \& Mioto (2007) destacan que una pesquisa bibliográfica difiere de una revisión bibliográfica, una vez que va más allá de la simple observación de datos presentes en pesquisas ya realizadas, imprimiendo teoría sobre ellas y vinculando una comprensión crítica. Por tanto, se considera que el presente estudio atiende a las exigencias de los teóricos, dado que expone cuales criterios utilizó para seleccionar el referencial teórico, la perspectiva que orienta el análisis y los objetivos que guían la pesquisa.

\section{Travestilidad y el Cruce de las Fronteras de Género}

Según Butler (2013), la sociedad occidental contemporánea suele restringir la vivencia de género a la cisgeneridad, o sea, a la plena concordancia del sujeto en vivir dentro de las expectativas oriundas del género que le fue socialmente designado 
al nascer. Por consiguiente, al ser leído por la sociedad como "niño", el individuo pasa a tener que incorporar características consideradas masculinas, así como vivir sus relaciones afectivas y sexuales con "mujeres". Mujeres, entre comillas, pues esa sociedad ignora la posibilidad de géneros femeninos que tengan un genital distinto al de hembra, así como considera hombres a todos aquellos que poseen un pene.

Esa importancia dada a la categorización de los cuerpos en géneros dimorfos que se excluyen mutuamente empieza en el siglo XVII, como demuestra el levante bibliográfico realizado por Laqueur (2001). Con motivaciones políticas, el discurso científico pasa a dar cada vez más atención a las diferencias biológicas entre hombres y mujeres, buscando relacionar esas distinciones al origen de muchos males y enfermedades. La lectura contemporánea de lo masculino y femenino, por lo tanto, se debe principalmente al discurso médico.

Los estudios queer retoman la discusión al respecto de cómo la distinción entre géneros no es natural, siendo fruto de normas de género que son creadas y reiteradas en las relaciones sociales (Miskolci, 2009). Butler (2014) explica que el género es performativo, o sea, socialmente construido y reiterado por las acciones de los sujetos. Gracias al aspecto cis y heterocentrado de esa sociedad, complementa, las performances son direccionadas a la heterosexualidad y cisgeneridad pues, caso contrario, existe el riesgo de segregación y violencia.

Aunque las consecuencias de transgredir las normas de género sean duras, Butler (2014) afirma que pueden ocurrir fisuras en el "cistema". Stryker (2017) afirma que esas corporalidades cruzan las fronteras de género, subvirtiendo lo binario, por lo cual las llama "trans". Las travestis son un ejemplo de esas expresiones de género que no pueden ser entendidas cuando se restringe a una percepción binaria.

Acerca de eso, expone Vale (2005) que el travestismo es también pasaje de un límite, travesía de una frontera o, en el sentido etimológico del término transgressio, una frontera visible a los ojos de todos, aquella de los géneros. Transgresión de fronteras y visibilidad son, por lo tanto, cuestiones centrales en esa experiencia.

En consecuencia, comprender el género de las travestis requiere analizar dislocamientos fronterizos, sea en lo que se refiere a los límites de la concepción binaria de género, cuanto a las fronteras geopolíticas. Por ello, se afirma que la travestilidad alude al tránsito, movimiento que las aparta de las expectativas de género del cistema, conforme será discutido.

Inicialmente, debe enfatizarse que utilizan el pronombre femenino, razpcomo Son "las" travestis, como destaca Lanz (2018). La utilización del pronombre femenino demuestra la fluidez de las expresiones de género, pues en la época en que Kulick (2008) escribe su famosa etnografía sobre travestis de Salvador, el pronombre recurrente era el masculino. El propio autor, al escribir el prefacio de la adaptación a libro de ese trabajo, resalta que muchos de los aspectos que analizó en su narrativa ya no se verifican en la realidad de las travestis brasileñas

Sobre las travestis, Cabral (2012, p.8) plantea que su género es "construido tanto a través de sus procesos de transformación corporal como de sus prácticas sexuales". Lo mismo es constatado por Kulick (2008) al examinar las relaciones de ellas con sus novios y clientes. El autor confirma la importancia de la práctica sexual para la identidad travesti pues observa que, aunque sientan placer desempeñando papeles sexuales considerados masculinos, estos quedan prohibidos en las relaciones con sus parejas. Utilizar el pene para penetrar durante el acto sexual es algo que ocurre apenas entre travesti y cliente, una vez que el novio o marido jamás podrá desempeñar un rol sexualmente pasivo. Esa recusa se debe a que es el papel sexual que desempeñan con sus parejas que les asegura cuan femeninas son. El hecho de que busquen novios que incorporen muchos aspectos socialmente considerados masculinos, tanto en la apariencia como en la performance sexual, está relacionado a esa importancia de afirmar su feminidad.

Consecuentemente, el novio de una travesti jamás debe excitarse con el genital de su compañera. Para ellas, un novio que desee tocar su pene está cometiendo una grave ofensa, comportándose de manera gay, siendo prontamente remplazado. Kulick (2008) afirma que pudo presenciar a algunas travestis luciéndose delante de las amigas al comentar al respecto de los 
celos sentidos por los novios, en una clara incorporación del modelo de relación afectiva hetero y cis centrada. Por el fuerte aspecto patriarcal de la sociedad brasileña, son comunes las dinámicas afectivas en las que el varón siente celos de su compañera e intenta ejercer alguna forma de control sobre ella, papeles de género que son apropiados por las travestis para, de esa manera, sentirse más cercanas a una vivencia "verdaderamente femenina".

A parte de las experiencias afectivas, la relación que establecen con sus cuerpos es fundamental para las travestis. El destaque otorgado a las modificaciones corporales surge de su búsqueda por una apariencia que sigue estándares de belleza que radicalizan la feminidad, moldeando sus cuerpos no con la finalidad de "pasar" por mujeres cisgénero. Desean, a cambio, características que las aproximen de la exuberancia, aborreciéndose de la "normalidad" de las amapô, palabra del dialecto pajubá que utilizan a fin de nombrar a las mujeres cis (Silva \& Santos, 2017). A través de ese proceso de modificación corporal se tornan bellas, clasificación que Pelúcio (2005a) explica como estético-moral, una vez que la bella travesti demuestra que se cuida, que no es "relajada".

La búsqueda por el cuerpo perfecto es, para las travestis, prácticamente sin fin. Desde el momento en que comprenden su identidad de género, ellas se dislocan con el propósito de poder viabilizar las transformaciones necesarias para moldear sus cuerpos y actitudes. Así pues, el próximo tópico presenta las razones que hacen con que se pueda afirmar que el dislocamiento de los gayzinhos hacia grandes ciudades es un momento central en las vivencias de género de las travestis.

\section{Migraciones Dentro de Brasil}

Cabral (2012) presenta el concepto de "migraciones travestis" para indicar los tránsitos que ellas realizan en el proceso de construir sus identidades. Vale (2005), por otro lado, utiliza la expresión "vuelos de la belleza" con la finalidad de nombrar esos dislocamientos, sobre todo cuando ocurren hacia Europa. Las reflexiones de ambos teóricos se complementan, de esa manera, al demostrar cómo esas migraciones son fundamentales para la experiencia travesti.

Por esa razón, las travestis que nacen y crecen en pequeñas o medianas ciudades realizan su primera migración rumbo a los grandes centros urbanos. En ellos, conocen a otras travestis y entran en contacto con el mercado sexual, a medida en que empiezan a modificar sus cuerpos. El contacto con amigas travestis les permite aprender cómo deben llevar los cabellos, uñas y maquillaje, así como conocer a las bombadeiras que las ayudarán a realizar las mudanzas corporales más decisivas.

Benedetti (2005) explica que las bombadeiras son mujeres, trans o cis, que aplican inyecciones de silicona industrial en los cuerpos de las travestis, con la finalidad de conferir curvas femeninas a sus cuerpos masculinos de gayzinho. Según Pelúcio (2005b), el nombre gayzinho es utilizado para designar a aquellas que aún no pueden ser llamadas de travesti, puesto que no tienen significativas modificaciones en sus cuerpos. Comúnmente, los gayzinhos apenas incorporan la feminidad en sus atuendos, lo que se debe a la imposibilidad de conocer bombadeiras en sus ciudades de origen y también al temor de tornarse travestis en una comunidad donde no son anónimas.

Esa percepción es encontrada en Vale (2005), quién relaciona las migraciones travestis al exilio. Para el autor, los tránsitos travestis pueden ser considerados una forma de autoexilio, pues percibe esa connotación en los relatos de muchas de ellas. Por esa razón, afirma que la busca por lugares más clementes supone dislocamientos, sea hacia grandes ciudades, sea hacia otros países.

Al llegar a las grandes ciudades, las travestis pasan a vivir la "noche", conforme categorizada por Pelúcio (2007). La autora explica que la noche es el espacio de las travestis, donde buscan clientes, socializan con las amigas y encuentran novios. Gracias al anonimato nocturno, pueden desenvolverse con relativa seguridad en una sociedad que tiene fobia de los cuerpos trans, como asevera Bento (2017) cuando expone que Brasil es el país que más mata travestis y transexuales en todo el mundo.

Los contactos que hacen en la "noche" les permiten adquirir el conocimiento necesario para ser una travesti. Pelúcio 
(2005b) explica que son cuatro los momentos vivenciados para "convertirse" en una travesti. Primero, son gayzinhos. Luego, empiezan a "montarse", incorporando atuendos femeninos y utilizando maquillaje. Seguidamente, pasan a "transformarse", vistiendo femeninamente con mayor frecuencia y, muchas veces, empezando a ingerir hormonas. Por fin, el momento final consiste en tornarse una travesti, donde las modificaciones son irreversibles y los atuendos femeninos están presentes las veinticuatro horas.

Puede ser observado que los saberes y técnicas necesarios para convertirse en travesti no existen en las pequeñas ciudades. El trabajo sexual - al cual recurren la gran mayoría de las travestis brasileñas (Leite Junior, 2014) - también es más rentable en los grandes centros urbanos, pues consiguen más clientes y pueden llegar a tener auxilio de una mãe o madrinha.

Sobre esa relación, Cabral afirma que el vínculo entre mãel madrinha y filha/afilhada tiene conotaciones múltiples, en las cuales se vislumbran aspectos económicos, sociales y también de poder. Pone como ejemplos la protección otorgada por la mãe a una recién llegada, así como los consejos recibidos de la madrinha sobre como portarse, montarse, etc. El respecto que obtiene a cambio ultrapasa el pagamiento pecuniario, una vez que la debe seguir las normas de convivencia determinadas por la mãe.

Por lo tanto, seria incorrecto decir que las mães y madrinhas son simplemente madamas. El vínculo que establecen con las travestis es mucho más complejo, pues envuelve no solo lo financiero, caracterizándose también por el respecto. En su labor etnográfico, Cabral (2012) encuentra muchos relatos de travestis que llevan buenas relaciones con sus mães y que consideran justos los castigos que estas aplican a quien no sigue las reglas.

Obviamente, no se pretende defender que todas las relaciones de las travestis con quienes ocupan rangos más altos en la jerarquía originada del trabajo sexual sean favorables. Lo que se busca destacar es de qué manera actores sociales como mães, bombadeiras y amigas travestis son fundamentales en esas trayectorias, ocupando papeles de destaque que se deben al carácter construido de sus identidades, las cuales no se podrían alcanzar sin la migración travesti.

Como se observa, las migraciones travestis tienen motivaciones que superan lo estético, pues es en los grandes centros urbanos que pueden construir redes de sociabilidad las cuales contribuirán para que hallen medios de subsistencia y establezcan vínculos afectivos o sexuales. No obstante, el deseo de alcanzar mejores condiciones de vida, así como de incorporar capital cultural y social, las lleva a trasladarse a lugares mucho más lejanos, conforme se discute en el siguiente tópico.

\section{Las Europeas}

Una vez transformadas en travestis, muchas tendrán interés en cruzar aún más fronteras. Abandonar el país es un sueño compartido por innúmeras de ellas, pues es así como llegan a ser “europeas”, categoría êmica utilizada para designar a las más bellas y sofisticadas travestis cuando regresan de una temporada en Europa.

Con respecto a esa relación, explica Vale (2005) que ultrapasar límites constituye el ethos mismo de la experiencia travesti y transgénero, a partir de aquello de nombran de 'proceso de feminidad', Europa posibilita la coronación de una vida vivida en fronteras y pasajes. En eses dislocamientos, Europa se presente como el 'sueño dorado' de personas que conocieron tempranamente la injusticia, la violencia domestica y encontraron en la venta de servicios sexuales una fuente de ingresos

Por tanto, más que la experiencia cosmopolita, Europa posibilita coronar una experiencia moldeada por el cruce de fronteras (Vale, 2005). No obstante, ser europea no es un emprendimiento simple. Envuelve arcar con el alto precio del viaje hacia Europa, adquiriendo deudas con las mães, por ejemplo. También significa ingresar en un territorio desconocido, donde la lengua y las costumbres son distintas. Pese a esos aspectos, el deseo de cruzar el océano Atlántico es encontrado frecuentemente en los estudios a respecto de las travestis (Teixeira, 2008). 
El flujo migratorio de las travestis rumbo a Europa remonta a los años setenta, época en que el destino favorito era Francia. Kulick (2008) destaca que apenas en los años noventa Italia se convierte en el destino travesti por excelencia, manteniéndose hasta los días actuales. Sin embargo, España y Francia también son importantes focos de migración travesti (Cabral, 2012).

Al respecto de la manera como logran migrar a los países europeos, Cabral (2012) y Teixeira (2008) defienden la existencia de redes de apoyo las cuales fornecen dinero, acomodaciones y demás contactos que facilitarán su llegada a Europa. No obstante, los autores no pretenden negar que puedan existir redes de trata y explotación de travestis que se aprovechen de su deseo de emigrar. Sus observaciones buscan destacar la complejidad de las redes utilizadas por travestis para poder realizar el viaje, así como demostrar la percepción que tienen de esas redes. De esa manera, según la opinión de las entrevistadas de Teixeira (2008), las travestis que van a Europa para ejercer la prostitución no son explotadas, pues ese también era el trabajo desempeñado en Brasil.

Sin embargo, es factible considerar que las frágiles condiciones de vida de las travestis en Brasil contribuyen para que no se sientan utilizadas en Europa. En consecuencia, aun cuando la situación vivida en el extranjero es precaria - lo cual es agravado por la condición de indocumentadas de muchas travestis - todavía se encuentra dentro de los parámetros de normalidad para esa población, razón por la cual difícilmente se consideran víctimas (Teixeira, 2008).

La prostitución travesti en, y para, Europa no es alimentada por la trata de seres humanos, y sí por la opresión material y simbólica que circunscribe a las travestis en guetos, dificultándoles el acceso a escolaridad, al mercado de trabajo y comprometiendo sus proyectos de transformación e inserción social fuera de la prostitución (Pelúcio, 2005b).

Becerra (2010) menciona cómo se precariza aún más el acceso al trabajo para las travestis en Europa puesto que, además de no poseer documentos, sufren dominaciones decurrentes de su género, raza y nacionalidad. No obstante, a pesar de que esos marcadores sociales contribuyan para que sean renegadas a funciones consideradas marginales por los europeos - tal cual es la prostitución - ocurre lo contrario cuando se trata del mercado sexual transnacional.

Debido a percepciones generizadas y racializadas de Brasil, el mercado sexual transnacional valora características corporales consideradas "típicamente brasileñas". Por ello, piel bronceada, formas voluptuosas y nalgas protuberantes son altamente requisitadas por los europeos. Esos atributos se relacionan a la concepción estereotipada, colonizadora que poseen de Brasil, construyendo lo que Pelúcio (2010, p. 201) nombra de "gramática erótica colonial". Por esa razón las travestis buscan promocionarse de acuerdo con esas exigencias, accionando características vinculadas al estereotipo brasileño para adquirir exotismo, popularidad y clientes.

Entre tanto, la incorporación de esos atributos "brasileños" es cuidadosa, ya que las travestis buscan equilibrar los signos corporales brasileños valorados en el mercado sexual transnacional con el patrón de belleza europeo. Esa es una de las múltiples estrategias utilizadas por las travestis para mejorar sus estadas en Europa, entre las cuales también se destacan el uso de páginas web para encontrar clientes y el empleo de recursos semánticos - como los diminutivos - al promocionarse en páginas de periódicos, de manera a no herir la masculinidad del cliente (Pelúcio, 2010).

Los relatos referentes a la vida en Europa son múltiplos. Vale (2005) presenta numerosas narrativas de travestis que se sintieron más respetadas y aceptadas en el extranjero. De modo distinto, algunas de las historias compartidas por Cabral (2012) y Teixeira (2008) demuestran dificultades de adaptación, así como persecución policial, la cual se agrava porque la mayoría de las travestis se encuentra indocumentada.

Se percibe que ni siempre el emprendimiento europeo es exitoso. Sin embargo, la adquisición del status de europea no depende solamente del período vivido en el extranjero, siendo muy importante el comportamiento ostentado en Brasil. Por lo tanto, el momento en que regresan al país es crucial para determinar si serán leídas como victoriosas europeas, una vez que ese 
triunfo es medido principalmente por adquisiciones materiales - casa, carro, etc. - y por los cuidados corporales que hayan incorporado.

Entre tanto, destaca Teixeira (2008), existen más valores asociados a la condición de europea, los cuales ultrapasan lo financiero. Una de las entrevistadas de Pelúcio (2005b) por ejemplo, determina que una europea debe hablar al menos dos idiomas. La posibilidad de frecuentar buenos restaurantes, establecer contacto con otras culturas y conocer sitios célebres como la soñada Paris - también son aspectos que motivan las travestis a tornarse europeas (Pelúcio, 2011). Por lo tanto, además del prestigio económico, europeas incorporan un capital cultural que no está al alcance de aquellas que permanecen en Brasil.

De esa manera, el deseo de trabajar en el mercado transnacional del sexo y el sueño de ser una 'europea' no vienen apenas de la necesidad de aumentar sus ganancias económicas, más bien representan principalmente la esperanza de una vida significativamente mejor, donde se cree que el glamour es indisociable del respeto y los literales riesgos de vida son cambiados por seguridad (Leite Junior, 2014).

A parte de los aspectos comentados, afirma Piscitelli (2007) que el tránsito de las travestis rumbo a Europa genera una economía transnacional, pues es común que ellas envíen dinero a sus familiares que permanecen en Brasil. Sobre eso, menciona Teixeira (2008) que el dinero ganado por travestis en el exterior circula en Brasil y es recurrente el relato de que el primer dinero ganado en Europa es destinado a la compra de una casa para la madre en Brasil. Por ende, considerase que ser europea también ejerce influencia en las relaciones parentales y afectivas de las travestis, una vez que el envío de dinero a parientes es, de acuerdo a Vale (2005), muchas veces utilizado por ellas para reestablecer vínculo con la familia.

Los datos referentes a la violencia contra travestis en Brasil infieren que los cuerpos de ellas son considerados abyectos por la sociedad brasileña (Bento, 2017). Por esa razón, las travestis son motivadas a desplazarse, llegando a los países europeos con sueños que ultrapasan los bienes materiales. Más que sobrevivir, desean vivir, gozar de experiencias culturales, gastronómicas, entre otras, que les permitan superar las dificultades sufridas en su tierra natal. Por ello, analizar su tránsito hacia Europa es relevante porque permite conocer una compleja serie de factores y valores asociados a esa decisión, siendo incorrecto considerar que es simplemente una busca por el lujo. La precaria condición de ciudadanía que poseen en Brasil contribuye para que se arriesgan en el extranjero, pues la indocumentación que viven en Europa no es demasiado distinta a lo que enfrentan en su país de origen. Podría, considerándose lo expuesto, decirse que ser europea confiere acceso a una posición de prestigio que les ofrece más seguridad, escapando de la abyección, a medida en que les otorga la posibilidad de ser admiradas.

\section{Consideraciones Finales}

Las travestis amplían la comprensión del género femenino, resignificando la propuesta beauvoriana en lo que vendría a ser "no se nace travesti, se convierte en una". En ese sentido, convertirse en una travesti es un proceso que se relaciona íntimamente a las migraciones travestis de las cuales hablan Cabral (2012) y Vale (2005).

Según Colling (2013), al hablar de identidades de género es necesario recordar que no se cree en un esencialismo inherente a ellas, una vez que son encontradas expresiones plurales dentro de la "misma" identidad de género. De igual manera, Butler (2004), afirma que las identidades de género tienen mucho más que ver con el deseo de crear unidad de actuación política de que con uniformizar las performances.

No obstante, al analizar narrativas travestis se encuentran innúmeras similitudes, especialmente se considera que es posible identificar en muchas narrativas travestis un conjunto de experiencias y características que las unen, entre las cuales se destaca el tránsito fronterizo. Ese movimiento de cruzar fronteras ocurre cuando desafían la normativa cisgénero referente a 
qué se considera masculino y femenino, incorporando un genital considerado de "macho" y, a la misma vez, moldeando sus cuerpos siguiendo patrones de belleza femenina oriundos del sistema social heteronormativo. Esos patrones, no obstante, son seguidos a fin de alcanzar una feminidad propria, más exuberante, no permitiendo que se las confunda con mujeres cisgénero.

Buscando alcanzar esa feminidad, gayzinhos abandonan sus ciudades hacia las metrópolis, donde adquirirán los saberes que les permitirán vivir "la noche" y convertirse en travestis. Por lo tanto, aparte de cruzar fronteras de género, las travestis cruzan límites geográficos en la búsqueda de la cadena de relaciones sociales que les posibilitarán modificar sus cuerpos y performances, adquiriendo el "derecho" de ser leídas como travestis.

Además de necesario para alcanzar el status de travesti, nuevos tránsitos fronterizos son obligatorios para las que deseen tornarse europeas, categoría êmica de mucha notoriedad entre ellas. Ser una europea, de ese modo, requiere pasar una temporada en Europa para conquistar capital económico y simbólico, obteniendo un prestigio que difícilmente seria logrado permaneciendo en Brasil.

Aunque teóricos como Cabral (2012) y Leite Junior (2014) comenten que ni siempre la experiencia europea es agradable para las travestis, la seducción de Europa se relaciona íntimamente a las precarias condiciones de vida en Brasil, sobre todo cuando se suma el racismo a la opresión de género. Por consiguiente, el deseo de ser europea puede ser considerado como la manera encontrada por las travestis para disfrutar de aspectos sociales y culturales que les son negados en Brasil debido a la transfobia.

Mediante lo analizado, se considera que el cruce fronterizo se encuentra en el ámago del género de las travestis. Sea en los primeros momentos de la construcción de sus performances, cuanto en los instantes en que se arriesgan en el mercado sexual transnacional europeo, muchos de los marcos de vida de ellas requieren dislocar límites, cruzando fronteras simbólicas y geográficas. Por esa razón, conocer las motivaciones por detrás de esos movimientos permite ampliar la comprensión al respecto de la travestilidad, contribuyendo para un entendimiento más fluido del género y de la sexualidad, así como observar la relación entre ciudadanía precaria y sus dislocamientos geográficos.

\section{Referencias}

Almeida, M. (2017). Fronteiras, territórios e territorialidades. Revista da ANPEGE, 2(02), 103-114. DOI: https://doi.org/10.5418/RA2005.0202.0009

Beauvoir, S. de (2009). O segundo sexo. (2a ed.). Rio de Janeiro: Nova Fronteira.

Becerra, A. G. (2010). Tacones, siliconas, hormonas: teoría feminista y experiencias trans en Bogotá (Disertación de maestría). Facultad de Ciencias Humanas, Escuela de Estudios de Género, Universidad Nacional de Colombia, Bogotá, Colombia. Recuperado de https://core.ac.uk/download/pdf/11053208.pdf

Benedetti, M. (2005). Toda feita: o corpo e o gênero das travestis. Rio de Janeiro: Garamond.

Bento, B. (2017).Transviad@s: gênero, sexualidade e direitos humanos. Salvador: EDUFBA.

Butler, J. (2003). O parentesco é sempre tido como heterossexual? Cadernos Pagu, (21), 219-260. DOI: https://dx.doi.org/10.1590/S010483332003000200010

Butler, J. (2004). Undoing gender. New York: Routledge.

Butler, J. (2013). Problemas de gênero: feminismo e subversão da identidade. (5 ed.). Rio de Janeiro: Civilização Brasileira.

Cabral, J.V. (2012). Geografía travesti: cuerpos, sexualidade y migraciones de travestis brasileñas (Rio de Janeiro - Barcelona). (Tesis de doctorado). Departamento de Antropologia Cultural e Historia de América y África, Universidad de Barcelona, Barcelona, España. Recuperado de https://www.tdx.cat/handle/10803/95889

Colling, L. (2013). A igualdade não faz meu gênero: Em defesa das políticas das diferenças para o respeito à diversidade sexual e de gênero no Brasil. Contemporânea - Revista de Sociologia, (2), 405-427. Recuperado de http://www.contemporanea.ufscar.br/index.php/contemporanea/article/viewFile/149/85

Duque, T. (2009). Montagens e desmontagens: vergonha, estigma e desejo na construção das travestilidades na adolescência. (Dissertação de mestrado). Centro de Educação e Ciências Humanas, Universidade Federal de São Carlos, São Carlos, São SP, Brasil. Recuperado de http://repositorio.ufscar.br/handle/ufscar/6702 
Research, Society and Development, v. 10, n. 3, e3021037965, 2021

(CC BY 4.0) | ISSN 2525-3409 | DOI: http://dx.doi.org/10.33448/rsd-v10i3.7965

Duque, T. (2018). "Lá não tem gay": fronteira e relações de vizinhança envolvendo gêneros dissidentes e sexualidades disparatadas em Corumbá (MS). Mneme - Revista de Humanidades, 18 (40), 111-124. Recuperado de: https://periodicos.ufrn.br/mneme/article/view/12275/9335.

Kulick, D. (2008). Travesti: prostituição, sexo, gênero e cultura no Brasil. Rio de Janeiro: Editora Fiocruz.

Lanz, L. (2018). Por que tenho medo de lhe dizer quem sou? In: Ribeiro, P. R. C. et al. (Org). Corpo, gênero e sexualidade: resistência e ocupa(ações) nos espaços de educação. (49-69). Rio Grande: Ed. Da FURG.

Laqueur, T. (2001). Inventando o sexo: Corpo e gênero dos gregos a Freud. Rio de Janeiro: Relume Dumará.

Leite Junior, J. (2014). Travestis brasileiras e exotismo sexual. Ciências Sociais Unisinos, 50(1), 41-47. Recuperado de 10.4013/csu.2014.50.1.05

Lima, T. C. S. de., \& Mioto, R. C. T. Procedimentos metodológicos na construção do conhecimento científico: a pesquisa bibliográfica. Rev. Katál, 10(spe), 37-45. DOI: https://doi.org/10.1590/S1414-49802007000300004

Miskolci, R. (2009). A teoria queer e a sociologia: o desafio de uma analítica da normalização. Sociologias, (21), 150-182. DOI: https://doi.org/10.1590/S1517-45222009000100008

Pelúcio, L. (2005a). "Toda quebrada na plástica" - Corporalidade e construção de gênero entre travestis paulistas. Campos - Revista de Antropologia, 6, 97112. DOI: http://dx.doi.org/10.5380/cam.v6i0.4509

Pelúcio, L. (2005b). Na noite nem todos os gatos são pardos: notas sobre a prostituição travesti. Cadernos Pagu, (25), 217-248. DOI: https://doi.org/10.1590/S0104-83332005000200009

Pelúcio, L. (2007). Nos nervos, na pele, na carne: uma etnografia sobre prostituição travesti e o modelo preventivo de AIDS. (Tese de doutorado). Centro de Educação e Ciências Humanas, Universidade Federal de São Carlos, São Carlos, SP, Brasil. Recuperado de http://repositorio.ufscar.br/handle/ufscar/1399

Pelúcio L. (2010). Exótica, erótica e travesti: nacionalidade e corporalidade no jogo das identidades no mercado transnacional do sexo. In: Castro, A. L. de (Org). Cultura contemporânea, identidades e sociabilidades: olhares sobre corpo, mídia e novas tecnologias. (197-213). São Paulo: Cultura Acadêmica.

Pelúcio, L. (2011). Corpos indóceis - a gramática erótica do sexo transnacional e as travestis que desafiam fronteiras. In: Souza, L. A. de., Sabatine, T. T., \& Magalhães, B. R. (Org). Michel Foucault: sexualidade, corpo e direito. (105-132). Marília: Oficina Universitária; São Paulo: Cultura Acadêmica.

Piscitelli, A. (2007). Sexo tropical em um país europeu: migração de brasileiras para a Itália no marco do "turismo sexual" internacional. Revista Estudos Feministas, 15(3), 717-744. DOI: http://dx.doi.org/10.1590/S0104-026X2007000300014

Silva, D. I. S. C., \& Santos, O. J. S. dos. (2017). Semântica, gênero e sexualidade: o conceito dos pajubás da comunidade LGBT. Revista Acadêmica Magistro, 2(16), 29-42. Recuperado de http://publicacoes.unigranrio.edu.br/index.php/magistro/article/download/4708/2548

Stryker, S. (2017). Transgender History: the roots of today's revolution. Berkeley: Seal Press.

Teixeira, F. do B. (2008). L'italia dei Divieti: entre o sonho de ser europeia e o babado da prostituição. Cadernos Pagu, (31), 275-308. DOI: https://doi.org/10.1590/S0104-83332008000200013

Vale, A. F. C. (2005). O vôo da beleza: travestilidade e devir minoritário. (Tese de doutorado). Departamento de Ciências Sociais, Universidade Federal do Ceará, Fortaleza, CE, Brasil. Recuperado de http://repositorio.ufc.br/handle/riufc/1251 